\title{
Tetraferrocenylporphyrins as active components of self-assembled monolayers on gold surface $\dagger$
}

\author{
Andrea Vecchi, ${ }^{a}$ Emanuela Gatto,${ }^{a}$ Barbara Floris, ${ }^{a}$ Valeria Conte, ${ }^{a}$ Mariano Venanzi, ${ }^{a}$ \\ Victor N. Nemykin ${ }^{b}$ and Pierluca Galloni ${ }^{a} a$
}

Received 13th February 2012, Accepted 3rd April 2012

DOI: $10.1039 / \mathrm{c} 2 \mathrm{cc} 31052 \mathrm{j}$

Novel tetraferrocenylporphyrins-containing self-assembled monolayers were prepared employing two different approaches. Self-assembled monolayers were characterized using UV-Vis spectroscopy and cyclic voltammetry (CV) whereas their photoelectrochemical properties were investigated by photocurrent generation (PG) experiments.

Porphyrin-based self-assembled monolayers (SAMs) were widely investigated in the last two decades, due to their remarkable electrochemical and photophysical properties that resulted in several molecular electronic applications. ${ }^{1}$ Because of their unique optical properties, porphyrins can be employed as sensitizers for photovoltaic ${ }^{2}$ nanoscale devices, sensors ${ }^{3}$ or as components of organic light emitting diodes. ${ }^{4}$ Furthermore, porphyrins possess easily accessible and stable cationic and anionic states that can be exploited in the construction of molecular wires, ${ }^{5}$ transistors ${ }^{6}$ and molecular memories. ${ }^{7}$ The introduction of redox-active substituents such as ferrocene in the meso or $\beta$-pyrrolic position results in additional redox processes thus extending their applicative potentiality. ${ }^{8}$ Indeed, polyferrocenyl compounds are known to show multi-redox processes which often lead to the formation of mixed-valence states. Mixed-valence species exhibit strong metal-metal coupling, which is responsible for magnetic coupling and unpaired electron density migration. ${ }^{9}$ These outstanding properties prompted us to thoroughly investigate a new polyferrocenyl-containing porphyrin and its metal complexes. Ferrocenyl groups are highly conjugated to the porphyrin core in both tetraferrocenylporphyrin $\left(\mathrm{H}_{2} \mathrm{TFcP}\right)$ and its metal complexes (MTFcP), thus strongly affecting the electronic structure. ${ }^{10}$ The whole absorption spectrum of $\mathrm{H}_{2} \mathrm{TFcP}$ is markedly red shifted with respect to the parent Tetraphenylporphyrin $\left(\mathrm{H}_{2} \mathrm{TPP}\right)$ and the bands are broadened, thus covering a wider part of the visible spectrum. ${ }^{10,11}$

\footnotetext{
${ }^{a}$ Dipartimento di Scienze e Tecnologie Chimiche,

Università di Roma"Tor Vergata", Via della Ricerca Scientifica, 00133 Rome, Italy.E-mail: galloni@scienze.uniroma2.it; Fax: +390672594328

${ }^{b}$ Department of Chemistry \& Biochemistry, 1039 University Drive, University of Minnesota Duluth, Duluth, MN 55812, USA

$\dagger$ Electronic supplementary information (ESI) available: preparation of SAMs, synthesis, characterization of mono-substituted $\mathrm{H}_{2} \mathrm{TFcP}$ and 11-( $N$-imidazolyl)-1-undecyl thioacetate and detailed experimental procedures. See DOI: $10.1039 / \mathrm{c} 2 \mathrm{cc} 31052 \mathrm{j}$
}

Mixed valence states can be easily obtained by the progressive oxidation of individual ferrocenyl groups. Moreover, the redox behaviour of the molecule was found to be strongly influenced by the polarity of the solvent and by the coordination ability of the electrolyte. In particular, four reversible single-electron oxidations were observed in a non-polar solvent with a non-coordinating electrolyte for either the metal free ${ }^{12}$ or the transition metal complexes. ${ }^{13}$ Despite these interesting properties, to the best of our knowledge, formation of the TFcP-based SAMs has never been reported. In this communication, we describe the preparation and characterization of novel TFcP-containing SAMs as well as a preliminary investigation on their photocurrent generation efficiency. Two different strategies were used to build the porphyrin-based SAMs shown in Fig. 1: a $\mathrm{H}_{2}$ TFcP mono-functionalized with a thioacetylhexanoyl group for covalent linking and the axial coordination of $\mathrm{ZnTFcP}$ to a pre-formed imidazole-containing monolayer. In both cases SAMs were prepared with the porphyrin either as the only building block (entries 1 and 3 in Fig. 1) or diluted with a shorter chain alkanethiol in a deposition ratio of $1: 5$ (entries 2 and 4 in Fig. 1). The mono-functionalized $\mathrm{H}_{2} \mathrm{TFcP}$ was prepared for the first time by a mixed condensation of two different ferrocencarboxyaldehydes with pyrrole (ESI $\dagger$ ). Both $\mathrm{H}_{2} \mathrm{TFcP}$ and the imidazole-containing ligand were attached to the surface by the corresponding thioacetate groups. $S$-Acetyl protecting groups underwent in situ cleavage upon exposure

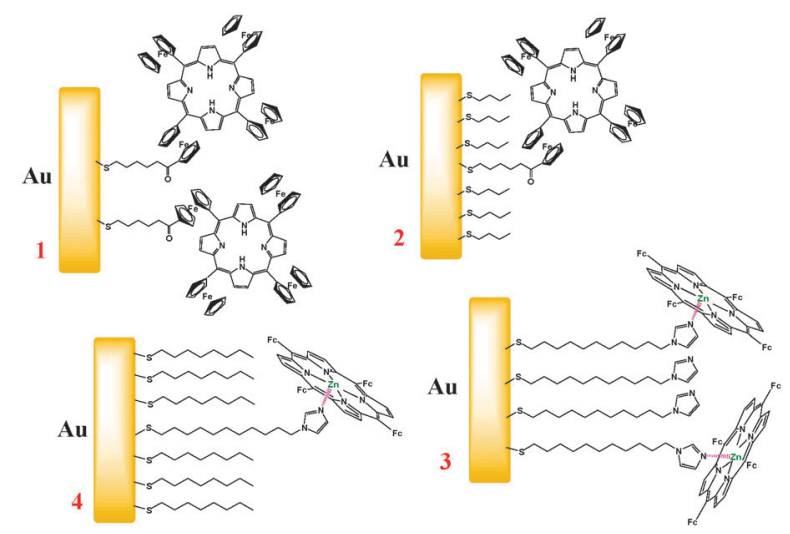

Fig. 1 Proposed structures of the SAMs prepared with: monosubstituted- $\mathrm{H}_{2} \mathrm{TFcP}$ (1) and mixed with BuSH 1:5 (2); thioacetate of 11-( $N$-imidazolyl)-1-undecyl-ZnTFcP (3) and mixed with OctSH $1: 5$ (4). 
to the gold surface, ${ }^{14}$ avoiding the handling of free-thiol compounds.

The degree of surface coverage was evaluated by quantifying the discharge of $\mathrm{K}_{3}\left[\mathrm{Fe}(\mathrm{CN})_{6}\right]$ on the modified electrode by $\mathrm{CV}$ measurements. ${ }^{15}$ In the case of mono-substituted $\mathrm{H}_{2} \mathrm{TFcP}$ the mixed SAM 2 showed a higher degree of packing with respect to 1, suggesting that, for the latter, steric hindrance effects inhibit the formation of a densely packed SAM. Indeed, upon switching from a single component monolayer (1) to a mixed one (2), the redox waves associated with ferricyanide disappeared completely $(\mathrm{ESI} \dagger)$. On the other hand, both the single component (3) and the mixed (4) SAMs showed complete coverage of the modified gold electrode before the coordination step. Furthermore, the oxidation potential of TFcPs was directly measured on the surface. The CV scans of $\mathbf{1}$ and $\mathbf{2}$ in a $\mathrm{MeCN} / \mathrm{TBAP}$ (TBAP = tetrabutylammonium perchlorate) system exhibited a reversible redox process in accordance with that reported for the parent $\mathrm{H}_{2} \mathrm{TFcP} .{ }^{12}$ In the same solvent/ electrolyte system, the four processes associated with the ferrocenyl moieties of $\mathrm{H}_{2} \mathrm{TFCP}$ occurred at the same potential $\left(E_{1 / 2}=+0.28 \mathrm{~V} v s . \mathrm{FcH} / \mathrm{FcH}^{+}\right)$. Since the functionalization differentiated one of the ferrocenyl groups, we were able to detect two distinct redox waves. Indeed, SAMs $\mathbf{1}$ and $\mathbf{2}$ showed a " $3+1$ " electron oxidation pattern (ESI $\dagger$ ) with the first three electron processes occurring at lower potentials and the last one, attributable to the substituted ferrocenyl group, observed at the highest potential (Fig. 2). The easy accessibility of wellseparated oxidation states opens the way for a feasible application in the field of molecular random access memories. ${ }^{7}$

The three electron oxidations were strongly shifted to negative potential when occuring on a gold surface (Fig. 3a and b). This difference is probably due to a decrease of the dielectric constant in the diffuse monolayer when compared to that of the bulk solution. ${ }^{16}$ Interestingly, a significant shift in the half-wave potential was found switching from $\mathbf{1}\left(E_{1 / 2}=+0.145 \mathrm{~V} v\right.$ s. $\left.\mathrm{FcH} / \mathrm{FcH}^{+}\right)$to $2\left(E_{1 / 2}=+0.185 \mathrm{~V} v s . \mathrm{FcH} / \mathrm{FcH}^{+}\right)$due to the introduction of 1-butanethiol. As for ZnTFcP-containing monolayers (Fig. 3c and d), in which the ferrocenyl groups are equivalent, we observed an irreversible, multielectron process in agreement with previous data in a less polar solvent. ${ }^{17}$ Interestingly, the opposite behaviour to SAMs $\mathbf{1}$ and $\mathbf{2}$ was found in SAMs 3 and $\mathbf{4}$ where the oxidation potential significantly decreased with the introduction of 1-octanethiol $\left[E_{\text {ox }}(3)=+0.28 \mathrm{~V}\right.$ and $\left.E_{\text {ox }}(\mathbf{4})=+0.19 \mathrm{~V} v s . \mathrm{FcH} / \mathrm{FcH}^{+}\right]$.

The integration of the anodic peaks yielded the density of porphyrins deposited on the electrode (ESI $\dagger$ ). As for the SAM

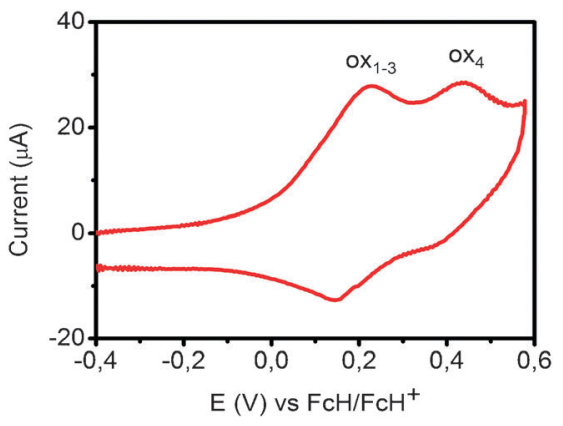

Fig. 2 First $\mathrm{CV}$ scan of 2 at $100 \mathrm{mV} \mathrm{s}^{-1}$.
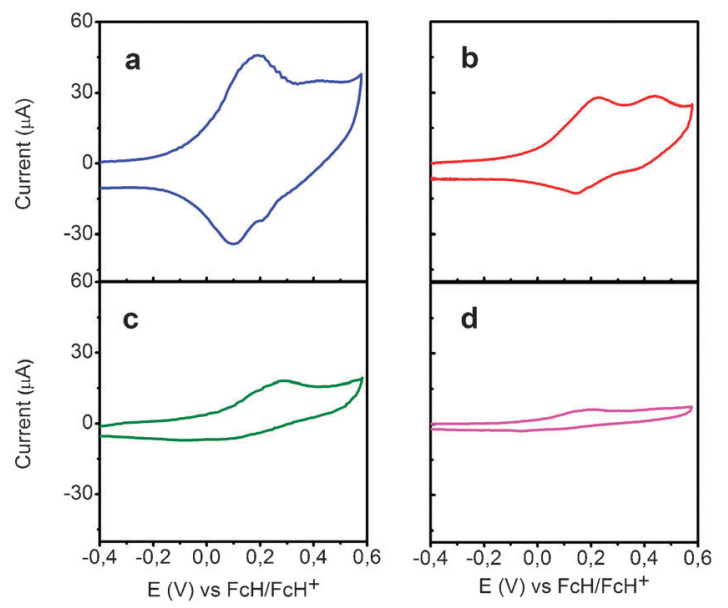

Fig. 3 CV scans of 1 (a), 2 (b), 3 (c) and 4 (d) at $100 \mathrm{mV} \mathrm{s}^{-1}$.

formed by the covalently bound porphyrin (1), we found an excellent density $\left[\Gamma_{\mathbf{1}}=(3 \pm 1) \times 10^{-10} \mathrm{~mol} \mathrm{~cm}{ }^{-2}\right]$. In the mixed SAM 2, the density of porphyrins was only three times lower with respect to $\mathbf{1}$, not maintaining the ratio of the coating solution $\left[\Gamma_{\mathbf{2}}=(1.1 \pm 0.8) \times 10^{-10} \mathrm{~mol} \mathrm{~cm}^{-2}\right]$. These data are in good agreement with the coverage experiment described above in which SAM 1 was not completely packed due to steric hindrance. These results suggest that $\mathrm{H}_{2} \mathrm{TFCPs}$ do not pack through $\pi-\pi$ interactions, probably because of the hindrance caused by the ferrocenyl groups. Interestingly, SAM 3 showed a porphyrin density $\left[\Gamma_{3}=(7.5 \pm 0.6) \times 10^{-11} \mathrm{~mol} \mathrm{~cm}^{-2}\right]$ five times higher than the amount found for the mixed SAM 4 $\left[\Gamma_{\mathbf{4}}=(1.6 \pm 0.4) \times 10^{-11} \mathrm{~mol} \mathrm{~cm}^{-2}\right]$. This evidence suggests a statistical deposition of imidazole-based ligand with octanethiol on gold. Since the interaction between ZnTFcP and its axial ligand is weaker than the covalent bond used in preparation $\mathbf{1}$ and 2, a lower density of porphyrins of about an order of magnitude was found in $\mathbf{3}$ and $\mathbf{4}$.

In all cases, a good stability of the monolayers was found and the signals remained unaltered for several cycles. Such stability, reversibility of the first three electron processes and electrochemical response make SAMs 1 and $\mathbf{2}$ suitable for chemical sensing applications. A further characterization of SAMs was made by UV-Vis spectroscopy on gold-supported glass. The absorption spectrum of SAM 1 shows a well-shaped Soret band slightly red shifted with respect to the same compound in solution (Fig. 4a). The intensity was too weak to detect the Q-bands. The UV-Vis spectrum of $\mathbf{3}$ (Fig. 4b) is dominated by a broadened Soret band with an intense and characteristic shoulder due to coordination. As expected from the above density results, $\mathbf{3}$ showed a weaker intensity

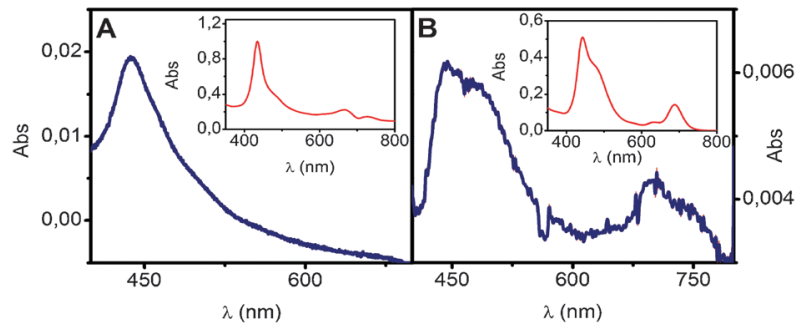

Fig. 4 Absorption spectra of $\mathbf{1}$ (a) and $\mathbf{3}$ (b) on gold-supported glass. Both the insets show the absorption spectra of the ligands in DCM. 
absorption than 1 but, surprisingly, an intense absorption of the Q-band was found.

Preliminary photocurrent generation experiments were also performed on selected SAM. Owing to the better packing that was found for mixed SAMs, PG experiments were carried out using gold electrodes modified by 2. Meso-arylporphyrins are well-known sensitizers for photocurrent generation and several papers have reported their properties. ${ }^{16,18}$ Imahori and Fukuzumi ${ }^{18}$ showed that an electron transfer can occur from an electron donor $($ TEOA $=$ triethanolamine) and the singlet excited state of such porphyrins. Although electrochemical experiments were carried out in a different solvent/electrolyte system, we took into account the oxidation potential measured for 2, i.e. $+0.185 \mathrm{~V} v$ s. $\mathrm{FcH}^{+} / \mathrm{FcH}$ (or $+0.60 \mathrm{~V} v$ s. $\mathrm{Ag} / \mathrm{AgCl}$ ). Since the oxidation of TEOA occurs approximately at the same potential $\left(E^{\mathrm{o}}=+0.61 \mathrm{~V} v s . \mathrm{Ag} / \mathrm{AgCl}\right)$ we assumed that the electron transfer from TEOA to monofunctionilized$\mathrm{H}_{2} \mathrm{TFcP}$ is slightly endoergonic. Indeed, as predicted by the above potential comparison, an intense cathodic photocurrent was detected. Hence, we proposed a reverse mechanism in which the excited porphyrin donates an electron to $\mathrm{O}_{2}\left(E^{\mathrm{O}}=-0.48 \mathrm{~V}\right.$ vs. $\left.\mathrm{Ag} / \mathrm{AgCl}\right) .{ }^{19}$ The resulting cationic porphyrin then rearranges to its reduced state by an electron transfer from the gold surface. As shown in Fig. 5, the Incident Photon to Current Efficiency (IPCE) spectrum of 2 at $0.0 \mathrm{~V}$ can be successfully superimposed to the absorption spectrum of monofunctionalized- $\mathrm{H}_{2} \mathrm{TFcP}$ in toluene, thus confirming the role of the porphyrin as the photoactive species of the monolayer.

In order to confirm the role of oxygen as the final electron acceptor of such a process, a control experiment was carried out in the absence of TEOA and in an $\mathrm{O}_{2}$ saturated aqueous solution. The resulting IPCE spectrum did not show any variation in shape or intensity with respect to that reported in Fig. 5. Moreover, the partial removal of $\mathrm{O}_{2}$ from the solution by a nitrogen stream resulted in an $85 \%$ decrease of the photoinduced current efficiency on the Soret band (ESI $\dagger$ ).

In summary, we successfully prepared novel tetraferrocenylporphyrin-containing SAMs using two different strategies: (i) covalent attachment of the monosubstituted metal-free porphyrin using a specific spacer, (ii) axial coordination of ZnTFcP to the pre-formed imidazole-containing SAM. The covalent approach yielded an excellent density of porphyrins

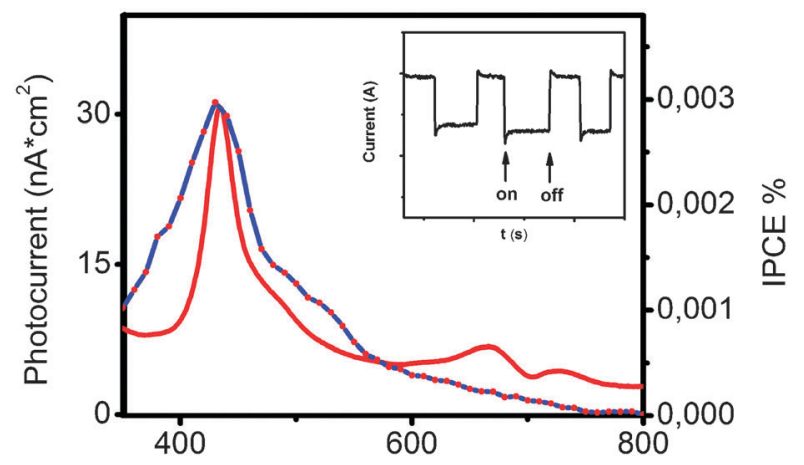

Fig. 5 Overlay of the IPCE spectrum of 2 (blue lines with red circles) at $0.0 \mathrm{~V}$ with the absorption spectrum of the mono-functionalized $\mathrm{H}_{2} \mathrm{TFcP}$ in toluene (red line). on the surface, while the second approach provided a simple, cheap and versatile method to functionalize pre-formed monolayers with metalloporphyrins. PG experiments were also performed with the mixed SAM 2 demonstrating that the asymmetric tetraferrocenylporphyrin constitutes the photoactive material of the photoelectrochemical cell. Interestingly, an intense cathodic photocurrent was generated at zero applied bias potential, most likely promoted by $\mathrm{O}_{2}$ reduction. These data, as well as the easy accessibility of different redox states of the monofunctionilized- $\mathrm{H}_{2} \mathrm{TFcP}$ monolayers, encourage the consideration of TFcPs as potential candidates for the construction of molecular electronic devices.

The financial support of MIUR (PRIN 20088NTBKR) is acknowledged. Generous support from the NSF CHE-1110455 to $\mathrm{VN}$ is greatly appreciated.

\section{Notes and references}

1 A. M. Jurow, A. E. Schuckman, J. D. Batteas and C. M. Drain, Coord. Chem. Rev., 2010, 254, 2297.

2 (a) H. Imahori, T. Umeyama and S. Ito, Acc. Chem. Res., 2009, 42, 1809; (b) H. Yamada, H. Imahori, Y. Nishimura, I. Yamazaki and S. Fukuzumi, Adv. Mater., 2002, 14, 892; (c) D. Wrobél, A. Siejak and P. Siejak, Sol. Energy Mater. Sol. Cells, 2010, 94, 492.

3 A. Ikeda, M. Nakasu, S. Ogasawara, H. Nakanishi, M. Nakamura and J.-I. Kikuchi, Org. Lett., 2009, 11, 1163.

4 L.-J. Zhu, Jian Wang, T.-G. Reng, C.-Y. Li, D.-C. Guo and C.-C. Guo, J. Phys. Org. Chem., 2009, 23, 190.

5 D. Holten, D. F. Bocian and J. S. Lindsay, Acc. Chem. Res., 2002, 35, 57.

6 P. B. Shea, L. R. Pattison, M. Kawano, C. Chen, J. Chen, P. Petroff, D. C. Martin, H. Yamada, N. Ono and Jerzy Kanicki, Synth. Met., 2007, 157, 190.

7 A. Balakumar, A. B. Lysenko, C. Carcel, V. L. Malinovskii, D. T. Gryko, K.-H. Schweikart, R. S. Loewe, A. A. Yasseri, Z. Liu, D. F. Bocian and J. S. Lindsey, J. Org. Chem., 2004, 69, 1435.

8 C. Bucher, C. H. Devillers, J. C. Moutet, G. Royal and E. SaintAman, Coord. Chem. Rev., 2009, 253, 21.

9 S. Barlow and D. O'Hare, Chem. Rev., 1997, 97, 637.

10 (a) V. N. Nemykin, C. D. Barrett, R. G. Hadt, R. I. Subbotin, A. Y. Maximov, E. V. Polshin and A. Y. Koposov, Dalton Trans., 2007, 3378-3389; (b) V. N. Nemykin and R. G. Hadt, J. Phys. Chem. A, 2010, 114, 12062.

11 V. N. Nemykin, P. Galloni, B. Floris, C. D. Barrett, R. G. Hadt, R. I. Subbotin, A. G. Marrani, R. Zanoni and N. M. Loim, Dalton Trans., 2008, 4233-4246.

12 V. N. Nemykin, G. T. Rohde, C. D. Barrett, R. G. Hadt, C. Bizzarri, P. Galloni, B. Floris, I. Nowik, R. H. Herber, A. G. Marrani, R. Zanoni and N. M. Loim, J. Am. Chem. Soc., 2009, 131, 14969.

13 G. T. Rhode, J. R. Sabin, C. D. Barret and V. N. Nemykin, New J. Chem., 2011, 35, 1440.

14 (a) M. I. Béthencourt, L. O. Srisombat, P. Chinwangso and T. R. Lee, Langmuir, 2009, 25, 1265; (b) J. M. Tour, LeRoy Jones II, D. L. Pearson, J. J. S. Lamba, T. P. Burgin, G. M. Whitesides, D. L. Allara, J. N. Parikh and S. V. Atre, J. Am. Chem. Soc., 1995, 117, 9529.

15 A. L. Eckermann, D. J. Feld, J. A. Shaw and T. J. Meade, Coord. Chem. Rev., 2010, 254, 1769.

16 H. Imahori, H. Norieda, Y. Nishimura, I. Yamakazi, K. Higuchi, N. Kato, T. Motohiro, H. Yamada, K. Tamaki, M. Arimura and Y. Sakata, J. Phys. Chem. B, 2000, 104, 1253.

17 P. Galloni, B. Floris, L. De Cola, E. Cecchetto and R. M. Williams, J. Phys. Chem. C, 2007, 111, 1517.

18 T. Hasobe, H. Imahori, H. Yamada, T. Sato, K. Ohkubu and S. Fukuzumi, Nano Lett., 2003, 3, 409.

19 H. Imahori, H. Norieda, H. Yamada, Y. Nishimura, I. Yamazaki, Y. Sakata and S. Fukuzumi, J. Am. Chem. Soc., 2001, 123, 100. 